\title{
Analyzing Climate Change Adaptation Strategies and Rural Farm Households' Income in Case Southern Ethiopia
}

\author{
Garedew Aweke Gizaw* \\ Lecturer of Department of Economics, College of Business and Economics, Dilla University, Ethiopia \\ Postal number: 419, Dilla University Ethiopia \\ Helina Abera \\ Lecturer of Department of Natural Resource Management, Dilla University, Ethiopia \\ Robel Hilegiyorgis \\ Lecturer of Department of Management, Dilla University, Ethiopia
}

The research is financed by Dilla University research and dissemination office.

\begin{abstract}
This study is an effort to determine the main determinants that affect farmers decision to adopt climate change mitigation practices and to assess the effect of climate change adaptation strategies on rural farm households' income in case of Southern Ethiopia. The study used primary data which is collected by questionnaires distributed for 374 farm households in 2020. In analyzing the data, the researcher employed both binary logit and Ordinary Least Square econometric regression. Binary logit model is employed to assess the factors affecting farmers decision to adopt climate change adaptation strategies in Southern Ethiopia and the Ordinary Least Square method is employed to know the effect of climate change adaptation strategies on rural farm households' income. The study confirms that climate change adaptation strategy is found to be significant in boosting famers' income level in the study area. Moreover, the main parameters that can affect farmers decision to mitigate climate change adaptation strategies are identified throughout the process. The implication is that local policy makers and the Zone's agricultural bureau have to work more on creation of awareness for farmers about the importance of climate change adaptation strategies.
\end{abstract}

Keywords: Climate change, adaptation strategies, household income.

DOI: $10.7176 / \mathrm{JESD} / 11-17-06$

Publication date:September $30^{\text {th }} 2020$

\section{Introduction}

Agricultural sector is the backbone for most developing countries economy. Despite of this significant contribution, Agriculture is the most vulnerable economic sector under climate change in developing countries. Different interpretations of climate change impacts on agriculture would lead to differences in districts strategy to address climate change. If the agriculture is believed to suffer from severe climate change, it will be more likely to adopt an aggressive policy toward climate change mitigation. If, instead, the belief is that climate change is not going to have negative effects, or will even be beneficial to the nation's agriculture, the nation's response to climate change will not be strong (Nath et al. 2011).

The vulnerability and poverty mapping in Africa according to ILRI (2006) puts Ethiopia as one of the most vulnerable countries to climate change with the least coping ability. Like other countries located in the tropics the most important climatic factors that influence crop yield in Ethiopia are seasonal rainfall and temperature. According to Reddy et al. (2007), more than $50 \%$ of variation in yield of crops is due to climatic variability. Although there is significant growth of the sector in the past few years, the country experienced a devastating drought last year which restricts the economic growth as well as the food security of households (FAO, 2016).

Adaptation practices to climate change refer to adjustment in natural and human systems in response to actual or expected climate changes. Many adaptation practices are mentioned in literatures and those are changing crop varieties, short season crops, drought resistant crops, crop diversification, adoption of soil and water conservation measures, tree planting, water harvesting, migration, chemical fertilizer, shifting farming practices from crop production to livestock herding, and changing dates of planting are the commonly used practices by farmers. Adaptation strategies are short and long-term changes to human activities that respond to the effects of changes in climate. In agriculture, adaptation will require cost-effective investments in water infrastructure, emergency preparation for and response to extreme weather events, development of resilient crop varieties that tolerate temperature and precipitation stresses, and new or improved land use and management practices. The rationale behind the implementation of adaptation measures is to improve the living standard of the poor households by reducing the impact of climate change (Ferede et al, 2014 as cited by Marye (2016) and Bewket et al, 2015).

It is fact that agricultural research and technological improvements are crucial to increasing agricultural productivity and thereby reducing poverty and meeting demands for food without irreversible degradation of the 
natural resource base. Di Falcao. S (2011) investigated the impact of climate change adaptation strategies in food security in case of Nile basin of Ethiopia. But the crop types producing in Nile basin Ethiopia and Southern Ethiopia are quite different. Therefore, to know the adaptive measures and their effectiveness on farmers' income level in Southern Ethiopia, a separate study in this area is needed.

In line with this, the major aim of this study is to identify the main factors that can affect farmers decision to adopt climate change adaptation strategies and to assess the effect of climate change adaptation practices on small holders' farmers' productivity which is proxied by their income level in Southern Ethiopia. Furthermore, the study hypothesized that whether household size, gender, education, farm size, access to credit and membership to farmerbased organizations have a significant effect on farmers' income level or not. The study used cross-sectional data from four purposely selected villages of Southern Ethiopia and employed econometric type of data analysis.

\section{Empirical Literature Review}

It is fact that climate change is one of a big environmental challenge facing humanity today. A paper done by Muburu et.al, (2015) in case of Kenya examines the adaptation strategies to climate change adopted by the dryland farming communities in Yatta district. The researchers included 510 participants randomly sampled small scale farmers. Both quantitative data and qualitative data were analyzed. The study concludes that farmers are engaging in adaptation strategies that are fundamentally changes in livelihoods and mainly unsustainable. Livelihood activities such as charcoal burning and sand harvesting in their fragile arid and semi-arid lands ecosystem are destructive and thus, not sustainable. These livelihood changes are significantly influenced by levels of education and climate change knowledge. The study recommends that agricultural extension services be enhanced to sensitize the farmers about climate change thus improving their perception and adaptation strategies.

Shisanya S. and Mafongoya P. (2016), done a study entitled adaptation to climate change and the impacts on household food security among rural farmers in South Africa. The researchers undertake their study on Mzinyathi District Municipality of Kwazulu-Natal. This study argued that households were concerned about their agricultural climate environment, overall represented by household vulnerability to climate change and this had direct impacts on household food security. Providing farmers with information on good agricultural practice, including water and soil management had direct impact on reducing the level of household food insecurity. Such information included coping mechanisms with regards to adverse climatic conditions hence the need for farmers' access to appropriate extension services.

Udin, et.al, (2014) examined a research on a case study of coastal Bangladesh. It examines four central components: firstly, the rate of self-reported adoption of adaptive mechanisms or coping strategies as a result of changes in climate; secondly, ranking the potential coping strategies based on their perceived importance; thirdly, identification of the socio-economic factors associated with adoption of coping strategies, and finally ranking potential constraints to adoption of coping strategies based on farmers' reporting on the degree to which they face these constraints. 100 farmers participated in the project's survey and logistic regression was employed. The result showed that a majority of the farmers self-identified as having engaged in adaptive behavior. Out of 14 adaptation strategies, irrigation ranked first among farm adaptive measures. The logit model explained that out of eight factors surveyed, age, education, family size, farm size, family income, and involvement in cooperatives were significantly related to self-reported adaptation. Despite different support and technological interventions being available, lack of available water, shortage of cultivable land and unpredictable weather ranked highest as the respondent group's constraints to coping with environmental degradation and change effects. These results provide policy makers and development service providers with important insight, which can be used to better target interventions which build promote or facilitate the adoption of coping mechanisms with potential to build resiliency to changing climate and resulting environmental impacts.

A study done by Bagamba et.al, (2012) investigated the debate on whether climate change will impact on people's livelihoods and, hence, the need to act is essentially over and has instead shifted to the development of strategies needed by different regions and countries to adapt to climate change effects. In this paper, by using the tradeoff analysis model, the impact of climate change on peoples' livelihoods and possible adaptation strategies to increase the resilience and sustainability of agricultural systems in three regions of Uganda which are central, Masaka and southwest; are analyzed. The results show that $70-97 \%$ of households will be adversely affected by climate change in Uganda. The southwest will be most affected due to smaller farm sizes and limited livelihood alternatives. There will be no positive gains from encroaching on swamps, which is one of the reported adaptation strategies to climate related stresses. Improving productivity of important crops (bananas for southwest, and sweet potatoes and bananas for central region); in addition to adoption of grade cattle are found to be a better adaptation strategy for climate change.

Tiwari et.al, (2015) done a paper entitled climate change impacts on rural farming and adaptation practices are new areas of study in the rural farming systems in three different agro-climatic regions of Nepal. Household survey, key informant interview and focus group discussion methods were applied to collect primary information at household and community levels supplemented with national climate data. It is observed that adaptation to 
climate change is location specific and determined by different factors. By using Logistic regression model, the study indicated different factors such as resources availability, family labor availability, farm income, institutional activities and involvement in the community level organization of households influenced adaptation practices. Local institutions are found to have limited capacity to implement the adaptation practices in the rural areas. Hence, the study suggested that planners and development workers should formulate location specific adaptation programs and activities focusing on water management for minimizing the impacts of climate change in rural farming in Nepal.

\section{Sampling Frame and Techniques}

A multi stage sampling technique is used to draw sample villages and small holder farm households. The sampling frame selected villages in such a way that each class in the sample match to the proportions for each class in the entire study area at the year 2020. Having these, four villages are selected through purposive sampling approach. During selection, the villages ecological, climatic condition and types of crops are considered to select the farm households in each village. The intended sample size is allocated to each village proportionally to population size of the selected village. As a representative sample Chichu, Tunitucha, Mochile Sissota and Akeshotum hafero are selected purposely. The total sample size of study is 374 farm households which are determined using the sample size determination formula of Yemane Taro (1963) as follows.

$$
n=\frac{N}{1+N(\alpha)^{2}}=\frac{5702}{1+5702(0.05)^{2}}=374
$$

Where $\mathrm{N}$, is the total households in the four Villages; $\mathrm{n}$ is the sample size and $\alpha$ is the level of significance for the present study and it is fixed at 5\%. The total number of farm households in Chichu is 1756, in Tunitucha 1543, in Mochile Sissota 1365 and in Akeshotum hafero is 1038. Hence, the total household in the four villages are 5702. The distribution of sample farm households is presented by the following table.

Table 1- Distribution of sample households

\begin{tabular}{lccc}
\hline \multicolumn{1}{c}{ Region } & Villages & Total households & Sample households \\
\hline \multirow{3}{*}{ Southern Ethiopia } & Chichu & & 99 \\
& Tunitucha & & 5702 \\
& Mochile Sissota & & 95 \\
& Akeshotum Hafero & & 82 \\
\hline Total & & $\mathbf{5 7 0 2}$ & $\mathbf{3 7 4}$ \\
\hline
\end{tabular}

\section{Conceptual Framework and the Empirical model}

The conceptual frame work of this study is dated back to the study of Roy (1951). In his study, Roy tries to show how individual's selects themselves between two different occupations, hunting and fishing based on their comparative advantage. The decision to participate in either of the two occupations is conditional on the benefit that will be generated from the occupations (Maddala, 1986). Similarly farm households will practice a given adaptation strategy by their own will. Households will select in their decision to adopt a given strategy. However, the decision to practice a given adaptation strategy will depend on the expected utility of adoption. The farmer will practice a given adaptation strategy if the utility from that strategy is greater than the remaining strategies. Thus, the decision for taking adaptation strategies can be modeled in a random utility framework (Difalco, 2011 and Kassie et al, 2011).

Let difference in utility from adoption and non-adoption is denoted by $\mathrm{T}$ and let represent by the following latent variable model (observable function).

$T_{h}=\beta_{z h}+\mu_{h}$

Where: $\mathrm{T}=1$ if a farmer practice at least one of the given adaptation strategies, $\mathrm{T}=0$ otherwise

$\beta=$ vector of parameters, $Z=$ vector of explanatory variables, $\mu=$ is the error term

Binary choice models are well-established models often used to analyze the adoption probability as it assumes occurrences between two alternatives (in this case being adopter or non-adopter of climate change adaptation strategies. The linear probability model which is expressed as a linear function of the explanatory variables is computationally simple. However, despite its computational simplicity, as indorsed by Gujarati (2004), it has a serious defect in that the predicted probability can be less than 0 or greater than 1 which violates the intuition that probabilities should be between 0 and 1 . The probit model is not preferred because of mathematical complexity like difficulty in interpretation and its strict assumption of normality.

Thus, the logistic regression model is an appropriate model, in this regard, to determine the influence of personal, socioeconomic and institutional factors on adoption of climate change adaptation strategies. In the 
logistic model, the coefficients are compared with the probability of an event occurring or not occurring and bounded between 0 and 1 . The dependent variable becomes the natural logarithm of the odds when a positive choice is made. The odds ratio and predicted probability of the independent variables indicate the influence of these variables on the likelihood of adoption of soil and water conservation technologies if other variables remain the same. Following Gujarati (2004), the Logistic regression model is specified as follows:

$$
P_{i}=E(Y=1 / x)=\frac{1}{1+e^{-}(\alpha+\beta 1 x 1)}
$$

For the case of explanation, we write (1) as;

$$
P_{i}=\mathbf{E}(Y=1 / x)=\frac{1}{1+e^{Z i}}
$$

Where $\mathrm{Z}_{\mathrm{i}}=\alpha+\beta 1 \times 1+\beta 2 \times 2+\cdots \cdots \cdots+\beta n \times n$

The probability that a given household adopting is expressed by (3) while the probability of not adopting is;

$1-p_{i}=\frac{1}{1+e^{Z i}}$

Therefore, we can write;

$\frac{\mathbf{P}_{\mathbf{i}}}{1-\mathbf{p}_{\mathrm{i}}}=\frac{1+\mathrm{e}^{\mathrm{Z}_{\mathrm{i}}}}{1+\mathrm{e}^{-Z_{\mathrm{i}}}}=\mathbf{x}^{\prime} \boldsymbol{\beta}+e$

Now, $(\mathrm{Pi} / 1-\mathrm{Pi})$ is simply the odds ratio in favor of adopting climate change adaptation strategies.

Where: $\mathrm{P}_{\mathrm{i}}$ : represents the probability of that $\mathrm{i}^{\text {th }}$ household making a certain choice (i.e. being adopter or nonadopter), for the given explanatory variables $\left(\mathrm{X}_{\mathrm{i}}\right) ; e$ : represents the base of natural logarithms (2.718); $Z_{\mathrm{i}}$ : is a function of $\mathrm{n}$ explanatory variables $\left(\mathrm{x}_{\mathrm{i}}\right), \mathrm{X}_{\mathrm{i}}$ : represents the $\mathrm{i}^{\text {th }}$ household explanatory variables, $\mathrm{n}_{\mathrm{i}}$ : represents the number of explanatory variables, $i=1,2,3 \ldots, n$, and $\alpha$ and $\beta$ represents regression parameters to be estimated, where $\alpha$ is the intercept and $\beta$ is the coefficients of $X_{i}$

Equation 1: Hence, to know and assess the factors affecting households' decision to adopt the climate change adaptation strategies or not the following final model is presented.

$a_{\text {ado }}=\beta_{0}+\beta_{1}$ gender $+\beta_{2} I+\beta_{3}$ age $+\beta_{4} e d u+\beta_{5} a c c+\beta_{6}$ land $+\beta_{7}$ fam $+\varepsilon_{h} \ldots$ (6)

Equation 2: Now we assume the relationship between agricultural productivity which is proxied by income of farm households, and adaptation strategies is linear. In this section we specify a model of climate change adaptation strategy and household income and the method that is employed is to include dummy variable by classifying farm households as adopters and non-adopters. And cross sectional ordinary least square regression method is employed. $I_{h}=\gamma X_{h}+\delta T_{h}+\varepsilon_{h}$ (7)

Where, $\mathrm{T}=$ the indicator of the adoption decision

$X_{h}=$ is other vectors of explanatory variables

$\gamma \& \delta$ - are vectors of parameters to be estimated and $\varepsilon$ is the error term.

If we run the above regression, the coefficient of adoption which measures the impact of practicing a given adaptation strategy/ies on income of the farm households is $\delta$.

Finally, to estimate the parameters, the empirical model is formulated as (Gujarity, 2004).

$I_{h}=\gamma X_{h}+\delta T_{h}+\varepsilon_{h}$; by expanding the vector $X_{h}$ we can rewrite this equation as:

$I_{h}=\gamma_{0}+\gamma_{1}$ ado $+\gamma_{2}$ gender $+\gamma_{3}$ age $+\gamma_{4} e d u+\gamma_{5} a c c+\gamma_{6}$ land $+\gamma_{7}$ fam $+\gamma_{8}$ mem +

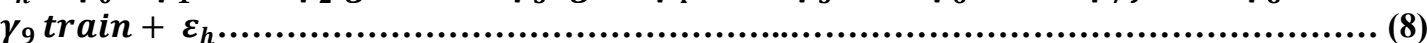

Where I= yearly income level of households (in birr)

ado $=$ dummy of farmers decision to adopt or not to adopt the strategies, $=1$ for adopters and $=0$ other wise, age $=$ age of households (in year), gender $=$ dummy of gender for the households, $=1$ for male and $=0$ for female, edu $=$ education level of households (year/ level of schooling), acc = dummy of access to credit for households, $=1$ for Yes and $=0$ for No, land = land size in hectare for each household (in hectare), fam = family size (Number of family members in household), mem $=$ dummy of membership to farm based associations/institutions, $=1$ for Yes and $=0$ for No train $=$ dummy of access for agricultural trainings, $=1$ for $Y$ es and $=0$ for No

$\beta i$ and $\gamma_{i}=$ parameters to be estimated

$\varepsilon_{h}=$ errorterm 


\section{Data analysis and presentation}

To check the reliability and verifiability of the estimated models, diagnostic tests are undertaken. Such tests are multicollinearity test, heteroscedasticity test and functional form/omitted variable test.

Multicollinearity Test: to test for whether the explanatory variables are correlated with each other or not, multicollinearity test through variance inflation factor is employed and the result

Confirms that there is no problem of multicollinearity in this model.

Heteroscedasticity test: heteroscedasticity problem is a circumstance in which the variability of the variable is unequal across the range of values of a second variable that predicts it. We estimated the model by using robust standard error. Due to this, the null hypothesis of no heteroscedasticity problem is accepted and there is constant variance in the model.

Functional form test: For Ramsey's RESET test, which tests whether the model suffers from omitted variable bias or not we failed to reject the null hypothesis of this test which says that the model is correctly specified, because the $p$-value is larger than the conventional significance value $(0.2614>0.05)$. Hence, the model is well specified and there is no variable which is omitted.

The Ramsey functional form test confirms that the model is specified well. This implies that the estimates are valid and unbiased.

Estimates of households' income level equation; Once we confirmed for the household's income level function in Southern Ethiopia is free from the above-mentioned problems, the next critical step is estimating the dependent variable on its explanatory variables. The results are reported in Table 2 below.

Table 2: Estimates of the effect of climate change adaptation strategies on farmers income level in southern Ethiopia.

\begin{tabular}{ccccc}
\hline $\begin{array}{c}\text { Dependent } \\
\text { variable (I) }\end{array}$ & Coefficient & $\begin{array}{c}\text { Robust } \\
\text { Standard error }\end{array}$ & t-value & p-value \\
\hline Gender & 19.84889 & 6.208338 & 3.20 & $0.002^{* *}$ \\
Age & -1.212562 & 2.093838 & -0.58 & 0.563 \\
Edu & 2.571486 & 1.339322 & 1.92 & 0.056 \\
Fam & -5.95491 & 1.845954 & -3.23 & $0.001^{* *}$ \\
Land & 1.764954 & 8.034883 & 0.22 & 0.826 \\
Mem & 2.354702 & 5.750901 & 0.41 & 0.682 \\
Acc & 22.83407 & 5.224505 & 4.37 & $0.000^{* *}$ \\
Ado & 19.87113 & 5.364109 & 3.70 & $0.000^{* *}$ \\
Train & 0.2410358 & 5.614223 & 0.04 & 0.966 \\
Constant & 85.80121 & 15.5806 & 5.51 & $0.000^{* *}$ \\
\hline Number of obs $=374$ & & $\mathrm{~F}(9,364)=7.49$ & $*$ significant at $5 \%$ & \\
R-squared $=0.1420$ & & Prob $>\mathrm{F}=0.0000$ & $* *$ significant at $1 \%$ & $1 \%$ \\
\hline
\end{tabular}

Source: Model output from STATA (2020)

Table 2 presents factors affecting income level of farm households in Southern Ethiopia including the target variable which is climate change adaptation strategies. The result shows that; gender of farm households, education level, family size, access to credit and adoption of mitigation practices are found to be significant in affecting farm household income level.

Since subsistence agriculture of Southern Ethiopia as well as Ethiopia is highly relying on rainfall, making an adjustment to the changing situation on climate change is crucial. According Rajan et al (2014) to the change on rainfall, temperature, humidity, speed and direction of wind, precipitation and humidity can adversely affects the productivity and income of farmers. Hence adaptation strategies are one of the mechanisms so as to give unbeatable solution to such problems and improve farm households' productivity and income level. The finding of this study is consistent with the existing literature and adoption of one of climate change mitigation practice is found to be positive and significant at $1 \%$ level of significance in affecting income level of farm households in the study area. The result confirms that, when farmers decides to adopt one of the adaptation strategies, their income level will positively be boosted than that of non-adopter farmers.

Regarding gender, being male household is positively and significantly affecting income level at $5 \%$ level of significance. This indicates income level increases with male households and decreases with female farm households. This may be due to in this study area as well as in Ethiopia farming is assumed to be job for males and the lion share of income from farming is allocated to male households. Another reason is those who are male farm households can do farming activity effectively and generate more revenue than female farm households.

Another variable which is found to be significant is education level of farm households. In the literature, it is thought that education is a significant determinant for technology adoption as well as income level of farmers. In line with this, the level of education for households and households' income level are positively related. Keeping other things remains constant; with an increase in education level, income level of farm households' increase and vice versa. This is due to formal education can bring the awareness of how farming activity can be done effectively 
and efficiently in turn results higher returns from this job.

Unfortunately, family size affects income level of those farm households negatively at 5\% level of significance. Citrus paribus, higher level of family size returns low level of income and the smaller the number of family size implies the higher the income of farm households. This may be due to decreasing trend in marginal productivity of labor with limited land size.

Access to credit is positive and significantly related to households' income, implying that the farm households' income level is higher for those farmers who have access to credit from different financial institutions compared to farmers not farmers who have access to credit. This result can be interpreted as an indication that access to credit from different financial institutions enables those farms to take relatively moderate investment in their farming activity and it enables those farmers to fulfill all necessary farm inputs in fair enough level. Access to training, land size, age of the households and member ship to agricultural associations or institutions are not statistically significant in the model. In certain ways these results are surprising in light of the existing theories and expectations Logit estimates of the adoption function: Binary choice models are well-established models often used to analyze the adoption probability as it assumes occurrences between two alternatives; in this case being adopter or non-adopter of climate change adaptation practices. The linear probability model which is expressed as a linear function of the explanatory variables is presented on the table below.

Table 3: Estimates of binary logit regression model which shows factors affecting farmers' decision to adopt climate change adaptation strategies.

\begin{tabular}{ccccc}
\hline $\begin{array}{c}\text { Dependent } \\
\text { variable (ado) }\end{array}$ & Coefficient & Standard error & z-value & p-value \\
\hline Gender & 0.6839754 & 0.3306779 & 2.07 & $0.039^{* *}$ \\
Age & 0.0179667 & 0.0968809 & 0.19 & 0.853 \\
I & 0.0086394 & 0.0023973 & 3.60 & $0.000^{*}$ \\
Edu & -0.0145082 & 0.0500281 & -0.29 & 0.772 \\
Acc & -0.0892911 & 0.2284391 & -0.39 & 0.696 \\
Fam & 0.0793703 & 0.0774792 & 1.02 & 0.306 \\
Land & -0.0646243 & 0.265741 & -0.24 & 0.808 \\
Constant & -1.455806 & 0.755505 & -1.93 & 0.054
\end{tabular}

Logistic regression

\begin{tabular}{lllll}
\hline Number of obs $=374$ & LR chi2(7) & $=22.38$ & $*$ significant at $5 \%$ \\
Prob $>$ chi $2=0.0022$ & Pseudo R2 & $=0.0439$ & $* *$ significant at $1 \%$ \\
\hline
\end{tabular}

Source: Model output from STATA (2020)

The findings of the binary logit regression model presented in Table 3 indicate that all variables except gender and income level are found to be insignificant in affecting adaptation strategies in the study area. gender of the households is positively and significantly affecting adaptation decision at $5 \%$ level of significance. This implies that the probability of adaptation of climate change mitigation practices significantly increases with male households and decreases with those who are female households. Female farmers have less interest or less incentive in taking climate change adaptation measures or they do not see the necessity to adapt to climate change effects in the study area. Moreover, income level of households is positively and significantly affecting the decision to adopt those mitigation practices. This implies that with higher income level of households the probability of adopting climate change mitigation strategies increase and with lower income level of those farm households the probability of adopting those climate change mitigation practices decreases. This is due to the need of financing those climate change adaptation strategies in the study area. But education, access to credit, age of farm households, land size and family size are found to be insignificant in explaining climate change adaptation practices equation. Marginal effects: Prediction of the effect of explanatory variables on adoption is possible by using marginal effects i.e. by partial differentiation with respect to each variable in the adoption function to indicate that the effects of a unit change in those variables on the expected value of adoption decision. Gender of household and income level of households is found to be significant factors determining the adoption of climate change mitigation practices in particular. But dummy of access to credit is found to be insignificant. 
Table 4: Marginal effects of explanatory variables on adoption decision of climate change mitigation practices.

\begin{tabular}{ccccc} 
Variable & $\mathbf{d y} / \mathbf{d x}$ & Standard error & z-value & p-value \\
\hline Gender* & 0.1691558 & 0.08092 & 2.09 & $0.037^{*}$ \\
Age & 0.0043744 & 0.02359 & 0.19 & 0.853 \\
I & 0.0021035 & 0.00058 & 3.62 & $0.000^{* *}$ \\
Edu & -0.0035324 & 0.01218 & -0.29 & 0.772 \\
acc* & -0.0217624 & 0.05572 & -0.39 & 0.696 \\
Fam & 0.0193246 & 0.01886 & 1.02 & 0.306 \\
Land & -0.0157343 & 0.0647 & -0.24 & 0.808 \\
\hline
\end{tabular}

$(*) \mathrm{dy} / \mathrm{dx}$ is for discrete change of dummy variable from 0 to $1 \quad *$ significant at $5 \% * *$ significant at $1 \%$ Source: Model output from STATA (2020)

The marginal effect results of the logistic regression presented in table 4 shows that, keeping other explanatory variables constant; being male household is significant in increasing the expected probability of adopting climate change mitigation practices in southern Ethiopia. That is, keeping other variables constant; being male farm household increases the expected probability of adopting climate change mitigation practices by about 0.169 . Similarly, one additional birr increase in farm households' income level will increase the expected probability of adopting climate change mitigation practices by about 0.002 , keeping all other variables being constant. Unfortunately, dummy of access to credit is found to be insignificant in affecting farmers decision to adopt climate change mitigation practices in southern Ethiopia.

\section{Conclusion and Implications}

This study is done to determine the effect of climate change adaptation strategies on rural farm households' income in case of Southern Ethiopia. In doing this, the study tried to answer the weather climate change adaptation strategies taken by the farmers can improve their income level or not. Furthermore, the study hypothesized the effect of other explanatory variables such as household size, gender, education level, and farm size in hectare, access to credit and membership to farmer-based associations on farmers' income level.

In doing this, the study used primary data which is collected by questionnaires distributed for sampled farm households. The sampling frame selected 4 villages by purposive sampling in such a way that each class in the sample match to the proportions for each class in the entire study area. Chichu, Tunitucha, Mochile Sissota and Akeshotum hafero Villages are selected and the totals of 374 farm households are selected.

The linear household's income level equation is estimated by cross sectional econometric method and after the pre estimation tests such as multicollinearity, heteroscedasticity and model specification tests; the regression result confirms that climate change adaptation practices have a strong positive and significant impact on farm households' income level at $1 \%$ level of significance. The result confirms that, keeping other variables constant; when farmers decide to adopt one of the adaptation strategies, it improves income level of farm households in the study area. Hence adaptation strategies are one of the mechanisms so as to give unbeatable solution to disasters which are caused by climate change on rainfall, temperature, humidity, precipitation and speed and direction of wind which in turn can improve farm households' productivity and income level.

Beyond the adoption decision of climate change mitigation practices, other explanatory variables such as sex, education and access to credit are found to be positively significant in affecting farmers' income level in the study area. Moreover, family size is found to be significant and negative in affecting income level of farm households. But Access to training, land size, age of the households and member ship to agricultural institutions are not statistically significant in the model.

\section{Implications:}

The findings of this study are very crucial for the effective development of strategies that are aimed to promote climate change adaptation practices so as to improve the income level of farm households in Southern Ethiopia. The positive and significant effect of climate change adaptation practices on farmers' income level encouraged and motivated for further implementation. Therefore, this study draws the following main policy implications.

$\checkmark \quad$ Local policy makers and agricultural bureau in the study area should give special attention in making farmers informed about the importance of adopting those climate change mitigation practices in improving their welfare specifically income level. This can be done by short-term trainings, agricultural extension services, giving low interest loans, and provision of facilities inputs and necessary equipment.

$\checkmark$ Giving incentives and rewards for those farmers who are adopters which in turn motivates those farmers who are not adopters previously. Those incentives can be financial subsidy or material support for those farmers.

$\checkmark$ Since access to credit positively affects their income level which in turn increases the probability of adopting climate change adaptation strategies, local policy makers, agricultural bureau and the 
concerned bodies in the study area have to deal with those farmers about the importance of short term and long-term loan for their farming activity. Moreover, farmers should have fairly enough access for loan giving institutions such as Banks, Microfinance and other rural saving and credit institutions.

Future research area: Future researches should focus on identifying specific adaptation measures which suits each different agro-ecologies and ranking of each adaptation mechanisms in each agro ecological areas.

\section{References}

Ashley Gorst, Ben Groom and Ali Dehlavi (2015). Crop productivity and adaptation to climate change in Pakistan. Centre for Climate Change Economics and Policy, Working Paper No. 214

Bewket, W., Radeny, M. A., \& Mungai, C. (2015). Agricultural adaptation and institutional responses to climate change vulnerability in Ethiopia.

Bagamba, F., Bashaasha, B., Claessens, I., \& Antle, J. (2012). Assessing climate change impacts and adaptation strategies for smallholder agricultural systems in Uganda. African Crop Science Journal, 20(2), 303-316.

Di Falco, S., Marcella Veronesi and Mahmud Yesuf, (2011., Does adaptation to climate change provide food security? Micro Evidence from Ethiopia. American Journal of Agricultural Economics 93 (3), 829-846.

FAO (2016). 2015-2016 El Niño early action and response for agriculture, food security and nutrition report draft. Working Draft (2 February 2016).

Ferede, T., \& Hailu, E. (2014). Credit constraints, adaptation to climate change and agricultural productivity. Panel data evidence from Rural Ethiopia.

IMF (2014). Country Report No. 14/303. Washington DC, USA.

Kassie, M., Shiferaw, B., \& Muricho, G. (2011). Agricultural technology, crop income, and poverty alleviation in Uganda. World development, 39(10), 1784-1795.

Maddala, G. S. (1986). Limited-dependent and qualitative variables in econometrics (No. 3). Cambridge university press.

Marye, F. A. (2016). The effect of climate change adaptation strategy on farm household's welfare in Nile Basin of Ethiopia: is there synergy or trade off? Masters Dissertation. Addis Ababa University, Ethiopia.

Mburu, B. K., Kung'u, J. B., \& Muriuki, J. N. (2015). Climate change adaptation strategies by small-scale farmers in Yatta District, Kenya. African Journal of Environmental Science and Technology, 9(9), 712-722.

Ministry of Trade (2015). Report on export performance of Ethiopia. Ministry of Trade, Federal Democratic Republic of Ethiopia, Addis Ababa, Ethiopia.

Mohammed Nasir Uddin, Wolfgang Bokelmann and Jason Scott Entsminger, (2014). Factors affecting farmers' adaptation strategies to environmental degradation and climate change effects. A farm Level Study in Bangladesh.

Reddy, S. R., Reddy, S. R., Reddi, C. H., Reddy, T. Y., \& Reddi, C. H. (2007). Principles of agronomy (pp. 359360). Kalyani Publishers.

Roy, A. D. (1951). Some thoughts on the distribution of earnings. Oxford economic papers, 3(2), 135-146.

Shisanya, S., \& Mafongoya, P. (2016). Adaptation to climate change and the impacts on household food security among rural farmers in uMzinyathi District of Kwazulu-Natal, South Africa. Food Security, 8(3), 597-608.

Thornton, P. K., Jones, P. G., Owiyo, T., Kruska, R. L., Herrero, M. T., Kristjanson, P. M., ... \& Omolo, A. (2006). Mapping climate vulnerability and poverty in Africa.

Tiwari, K. R., Rayamajhi, S., Pokharel, R. K., \& Balla, M. K. (2014). Determinants of the climate change adaptation in rural farming in Nepal Himalaya. International Journal of Multidisciplinary and Current Research, 2, 234-240.

World Bank (2017). World Development Indicators Database. Washington DC, U.S.A. 